\title{
The diagnostic value of magnetic resonance imaging measurements for assessing cervical spinal canal stenosis
}

\author{
*Tabea B. Rüegg, MMed, ${ }^{1}$ Anina G. Wicki, MMed, ${ }^{1}$ Nikolaus Aebli, MD, PhD, ${ }^{2-4}$ \\ Christian Wisianowsky, MD, ${ }^{5}$ and Jörg Krebs, PhD'
}

${ }^{1}$ Clinical Trial Unit, Swiss Paraplegic Centre, Nottwil; ${ }^{2}$ Spinal Medicine and Surgery, AndreasKlinik, Cham Zug; ${ }^{3}$ Orthopaedic Department, Medical Faculty, University of Basel, Switzerland; ${ }^{4}$ School of Medicine, Griffith University, Gold Coast, Queensland, Australia; and ${ }^{5}$ Radiology, Swiss Paraplegic Centre, Nottwil, Switzerland

OBJECT The authors investigated the relevance of 2D MRI measurements for the diagnosis of critical cervical spinal canal stenosis. Among patients who had sustained a minor cervical spine trauma, they compared MRI measurements of the cervical spine between those with acute cervical spinal cord injury (CSCl) and those without. They also investigated the correlation between the MRI measurements and the severity of $\mathrm{CSCl}$ as well as classification accuracy concerning the diagnosis of critical spinal canal stenosis for acute $\mathrm{CSCl}$ after a minor trauma.

METHODS The authors conducted a single-center retrospective radiological case-control study of patients who had sustained CSCl after a minor trauma to the cervical spine from January 2000 to August 2010. The controls were patients who had sustained a cervical trauma without clinical or radiological signs of cervical spinal cord pathology.

On axial T2-weighted MR images, the following were measured: the transverse spinal canal and cord area, the transverse and sagittal cord diameter, and the sagittal canal diameter of the cervical spine (C3-7). Using these measurements, the authors calculated the cord-canal-area ratio by dividing the transverse cord area by the transverse canal area, the space available for the cord by subtracting the sagittal canal diameter from the sagittal cord diameter, and the compression ratio by dividing the transverse cord diameter by its sagittal diameter.

The severity of $\mathrm{CSCl}$ was assessed by using the motor index scores of 10 key muscles at different time points (initially, 1 , 3 , and 12 months after injury) obtained from the clinical records.

The intra- and interobserver reliability of the MRI measurements, intra- and intergroup differences, and correlations between variables were also investigated. Receiver operating characteristic curves were calculated for evaluating the classification accuracy of the imaging variables for $\mathrm{CSCl}$.

RESULTS Data for $52 \mathrm{CSCl}$ patients and 77 control patients were analyzed. The intra- and interobserver reliability regarding the MRI measurements ranged from good (0.72) to perfect (0.99). Differences between the $\mathrm{CSCl}$ group and the control group were significant $(p<0.001)$ for all parameters, except for the cord area. The most prominent differences between the groups existed for the spinal canal area, cord-canal-area ratio, and space available for the cord. The classification accuracy was best for the cord-canal-area ratio and the space available for the cord; areas under the curve were $0.99(95 \% \mathrm{Cl} 0.97-1.0)$ and 0.98 (95\% Cl 0.95-0.99), respectively. There was no significant $(p>0.05)$ correlation between any of the imaging parameters and the motor index score at any time point.

CONCLUSIONS The cord-canal-area ratio ( $>0.8)$ or the space available for the cord $(<1.2 \mathrm{~mm}$ ) measured on MR images can be used to reliably identify patients at risk for acute $\mathrm{CSCl}$ after a minor trauma to the cervical spine. However, there does not seem to be any association between spinal canal imaging characteristics and the severity of or recovery from $\mathrm{CSCl}$ after a minor trauma.

http://thejns.org/doi/abs/10.3171/2014.10.SPINE14346

KEY WORDS cervical spine; spinal cord injury; minor trauma; spinal canal stenosis; MRl; cord-canal-area ratio; space available for cord

ABBREVIATIONS ASIA = American Spinal Injury Association; $\mathrm{CSCI}=$ cervical spinal cord injury; MIS = motor index score; $\mathrm{ROC}=$ receiver operating characteristic; $\mathrm{RR}=$ recovery rate; TPR = Torg-Pavlov ratio.

SUBMITTED April 10, 2014. ACCEPTED October 28, 2014.

INCLUDE WHEN CITING Published online December 19, 2014; DOI: 10.3171/2014.10.SPINE14346.

DISCLOSURE The authors report no conflict of interest concerning the materials or methods used in this study or the findings specified in this paper.

* Ms. Rüegg and Ms. Wicki contributed equally to this work and should be considered co-first authors. 
$\mathrm{A}$ CUTE cervical spinal cord injury (CSCI) can occur after a hyperextension or hyperflexion trauma to the neck despite only minor trauma (i.e., no osseous or discoligamentous injury), as a result of cervical spinal canal stenosis.,14,16 Presently, the Torg-Pavlov ratio (TPR) ${ }^{19}$ (ratio of the spinal canal to the vertebral body) is commonly used to assess (congenital) cervical spinal canal stenosis on conventional radiographs. However, the low positive predictive value of the TPR represents a major disadvantage. . $7,13,18$ Spondylotic changes, which most commonly occur in the vicinity of the intervertebral disc, and canal narrowing caused by soft tissue cannot be assessed with the TPR. ${ }^{6,20}$

There is evidence that MRI parameters are more suitable for the evaluation of cervical spinal canal stenosis.,13 The intra- and interobserver reliability of MRI parameters such as the transverse spinal cord area, the cord compression ratio (ratio transverse: sagittal cord diameter), and the sagittal canal diameter have been good. ${ }^{1,8}$ These MRI parameters have been investigated for athletes with cervical spinal neurapraxia ${ }^{13,17}$ and for Asian persons with chronic spondylotic cervical myelopathy. ${ }^{11,15}$ However, the relevance of the transverse spinal cord and canal area and the spinal cord compression ratio for the diagnosis of critical cervical spinal canal stenosis and the prediction of the severity of acute CSCI after a minor trauma to the cervical spine has not been investigated.

We therefore retrospectively investigated the transverse spinal cord and canal area as well as the spinal cord compression ratio in patients after a minor trauma to the cervical spine. We tested the hypotheses that in patients who sustained a minor trauma to the cervical spine, significant differences would be found in the transverse spinal cord area, the transverse spinal canal area, and the spinal cord compression ratio between those with acute CSCI and those without. Furthermore, we investigated the correlation between the transverse spinal cord or canal area or the spinal cord compression ratio and the severity of CSCI (motor index score [MIS]). We also investigated the classification accuracy of the spinal cord and canal areas as well as the compression ratio concerning the diagnosis of critical spinal canal stenosis for acute CSCI after a minor trauma to the cervical spine.

\section{Methods \\ Patient Populations}

Approval for this single-center study at the Swiss Paraplegic Centre, Nottwil, Switzerland, was granted by the local ethics committee. All patient data were made anonymous and kept confidential.

Patients with acute traumatic CSCI were identified by reviewing our database for patients who had consecutively sustained injuries that caused tetraplegia or tetraparesis (American Spinal Injury Association [ASIA] Impairment Scale A-D) from January 2000 to August 2010. We excluded from the study those patients with nontraumatic CSCI, those with preceding neurological symptoms, and those without radiological signs of CSCI (i.e., hyperintense signals in the spinal cord on T2-weighted sagittal MR images indicating edema or hemorrhage). To limit our study to patients with minor cervical spine trauma, we applied the following exclusion criteria: fractures (except for isolated fractures of spinous processes) and discoligamentous injuries of the cervical spine (assessed on MR images). We also excluded patients with gunshot, stabbing, or highvoltage current injuries and patients younger than 20 years.

The control group consisted of patients who had consecutively sustained a flexion-extension trauma to the cervical spine without clinical or radiological signs of cervical spinal cord pathology from January 2000 to August 2010 and who were admitted to the Swiss Paraplegic Centre. Patients with a history of cervical spinal cord disorders were excluded. To ensure that age ranges of patients in both groups were similar, we excluded from the control group those patients who were younger than 35 or older than 80 years.

Patient characteristics were collected from the electronic patient charts (MedFolio 2.2, Nexus AG).

\section{Imaging Measurements}

Measurements were taken from conventional radiographs and axial T2-weighted MR images of the cervical spine in neutral position from the C-3 to the $\mathrm{C}-7$ vertebral body. We used Phoenix PACS software (version 2.2.0.1815, release 3.0; Phoenix-PACS $\mathrm{GmbH}$ ) and recorded to the nearest $0.1 \mathrm{~mm} / \mathrm{mm}^{2}$.

On the conventional radiographs, we measured the sagittal diameter of the vertebral body and the spinal canal from the midpoint of the posterior aspect of the vertebral body (Fig. 1); we then calculated the TPR by dividing the spinal canal diameter by the vertebral body diameter. ${ }^{19}$ The TPR is an established parameter for assessing spinal canal stenosis.

On the axial MR images, the following parameters were measured: the transverse spinal canal and cord area, the transverse and sagittal cord diameter, and the sagittal canal diameter (Fig. 2). Measurements were taken at the level of the intervertebral disc. To delineate between the subarachnoid space and ligamentous or osseous structures, we set the border of the spinal canal area (i.e., the subarachnoid space) along the inner border of low signal intensity (Fig. 2). ${ }^{4,11}$ Using these measurements, we calculated the following parameters: the cord-canal-area ratio, by dividing the transverse cord area by the transverse canal area; ${ }^{11,12}$ the space available for the cord, by subtracting the sagittal canal diameter from the sagittal cord diameter; ${ }^{13}$ and the compression ratio, by dividing the transverse cord diameter by its sagittal diameter. ${ }^{4,8}$

For investigating the intra- and interobserver reliability of the MRI measurements, all parameters were measured in triplicate by 2 observers for 10 randomly chosen patients (5 from each group).

\section{Motor Index Score}

The MISs established at the following time points were extracted from the clinical records (electronic and paper charts): initial MIS (within 2 weeks after CSCI), MIS after 1 and 3 months (MIS1 and MIS3, respectively), and MIS after 12 months (MIS12). The key muscles were evaluated by occupational therapists according to 


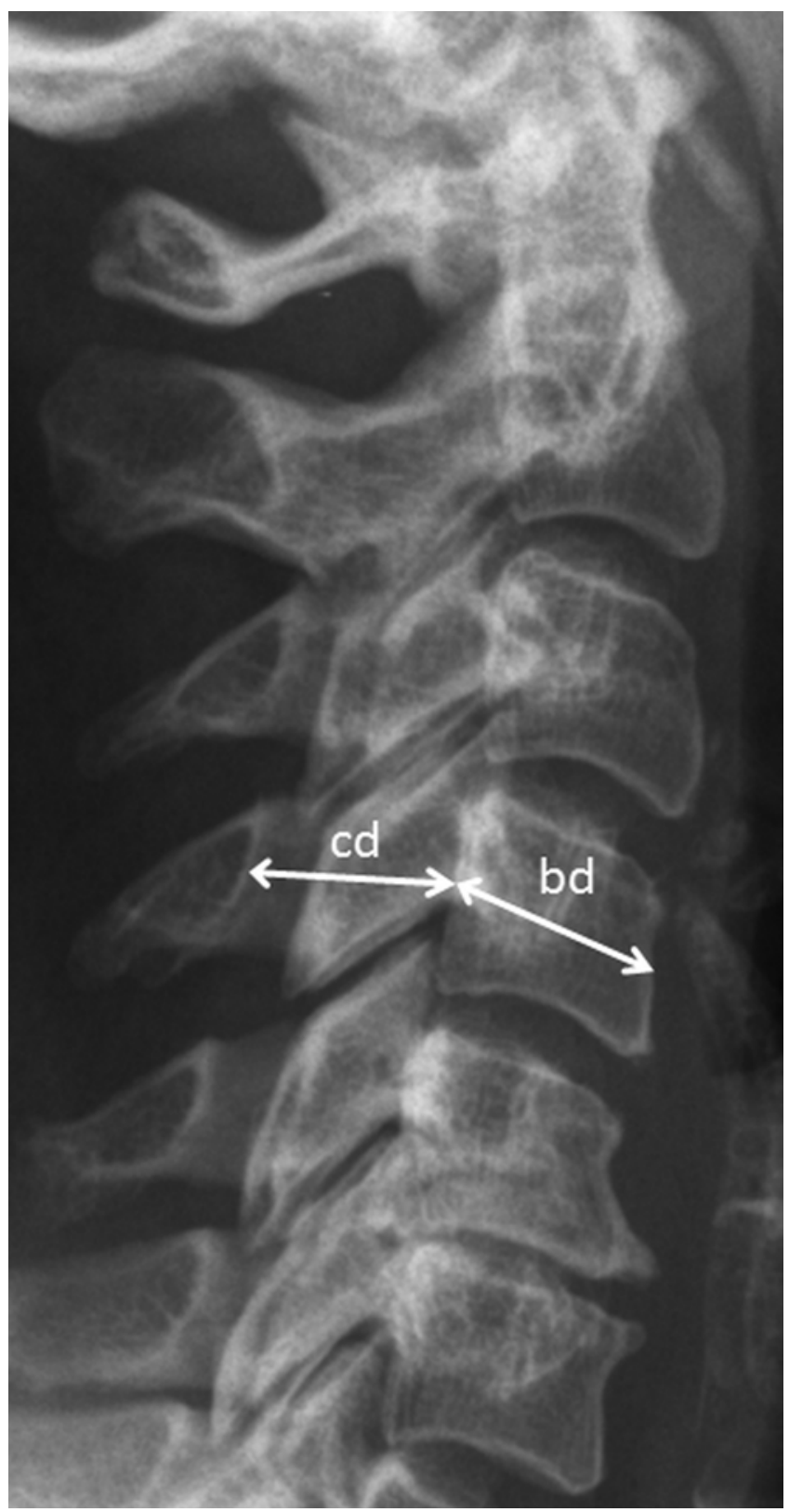

FIG. 1. Conventional lateral radiograph of the cervical spine with the measurements used to calculate the TPR; $b d$ indicates the sagittal diameter of the vertebral body measured between the midpoints of the anterior and posterior surfaces; $c d$ indicates the sagittal diameter of the spinal canal measured as the shortest distance from the midpoint of the posterior surface of the vertebral body to the spinolaminar line.

the ASIA guidelines. ${ }^{5}$ The MIS improvement at 1,3 , and 12 months was calculated by subtracting the initial MIS (MIS $_{\text {initial }}$ ) from the MIS of the respective time point (i.e., MIS1, MIS3, or MIS12). The recovery rate (RR) ${ }^{9}$ at the 3 follow-up time points was calculated using the following formulas: RR1 $=\left(\right.$ MIS1 - MIS $\left._{\text {initial }}\right) /\left(100-\mathrm{MIS}_{\text {initial }}\right), \mathrm{RR} 3$ $=\left(\mathrm{MIS} 3-\mathrm{MIS}_{\text {initial }}\right) /\left(100-\mathrm{MIS}_{\text {initial }}\right)$, and RR12 $=($ MIS12 - $\left.\operatorname{MIS}_{\text {initial }}\right) /\left(100-\right.$ MIS $\left._{\text {initial }}\right)$.

\section{Statistical Analysis}

Data were calculated as medians and $95 \%$ confidence intervals. Intraclass correlation coefficient analysis for absolute agreement of single measures was used to test for intra- and interobserver reliability of the measurements on the MR images. The intra- and intergroup differences were tested by using the Wilcoxon signed-rank and ranksum tests, respectively. Spearman rank-order analysis was used to investigate correlations between variables. Receiver operating characteristic (ROC) curves were calculated for evaluating the classification accuracy of the imaging variables for CSCI. Only the minimal or maximal values of each patient were used for ROC curve analysis. A p value $<0.05$ was considered significant for all statistical analyses. Statistical analyses were performed by using SPSS software version 18.0 (IBM).

\section{Results}

\section{Patient Populations}

Data for 52 CSCI and 77 control patients were analyzed. Patient characteristics are presented in Table 1. At admission, the ASIA Impairment Scale scores among the 52 CSCI patients were A for 14 (27\%), B for $12(23 \%), C$ for $9(17 \%)$, and D for $17(33 \%)$. At discharge, these scores for the same 52 patients were A for $4(8 \%)$, B for $7(13 \%)$, $\mathrm{C}$ for $9(17 \%), \mathrm{D}$ for $24(46 \%)$, and $\mathrm{E}$ for $8(15 \%)$. Of the 52 patients, neurological status improved partially in 26 $(50 \%)$ and not at all in 18 (35\%); $27 \%$ of patients had undergone decompression surgery and fusion.

\section{Imaging Measurements}

The intra- and interobserver reliability regarding the MRI measurements ranged from good (0.72) to perfect (0.99) (Table 2).

The measured and calculated imaging parameters for assessing cervical spinal canal stenosis are presented in Table 3. Differences between the CSCI and control groups differed significantly $(\mathrm{p}<0.001)$ for all parameters except the transverse cord area and the transverse cord diameter. The most prominent differences between the groups existed for sagittal canal diameter, spinal canal area, cordcanal-area ratio, and space available for cord.

The results from the classification accuracy analysis of the different parameters for the diagnosis of acute CSCI after a minor trauma to the cervical spine are presented in Table 4. The transverse cord diameter and area were not submitted to classification accuracy analysis because there was no significant difference between the 2 groups. The classification accuracy for CSCI after a minor trauma was best for the cord-canal-area ratio and the space available for cord with areas under the curve of 0.99 (95\% CI $0.97-$ $1.0)$ and 0.98 (95\% CI 0.95-0.99), respectively. The cord compression ratio was significantly inferior to the other MRI parameters (no overlap of $95 \%$ CI for area under the curve; Table 4).

\section{Motor Index Score}

The initial MIS of the CSCI patients after the trauma was 24.5 (95\% CI 2.5-99.1) out of 100, as presented in Table 5 . Two patients had sustained only sensory deficits, and thus the initial MIS was 100. After 1 month, $23 \%$ of the neurological recovery potential had been achieved (RR): 

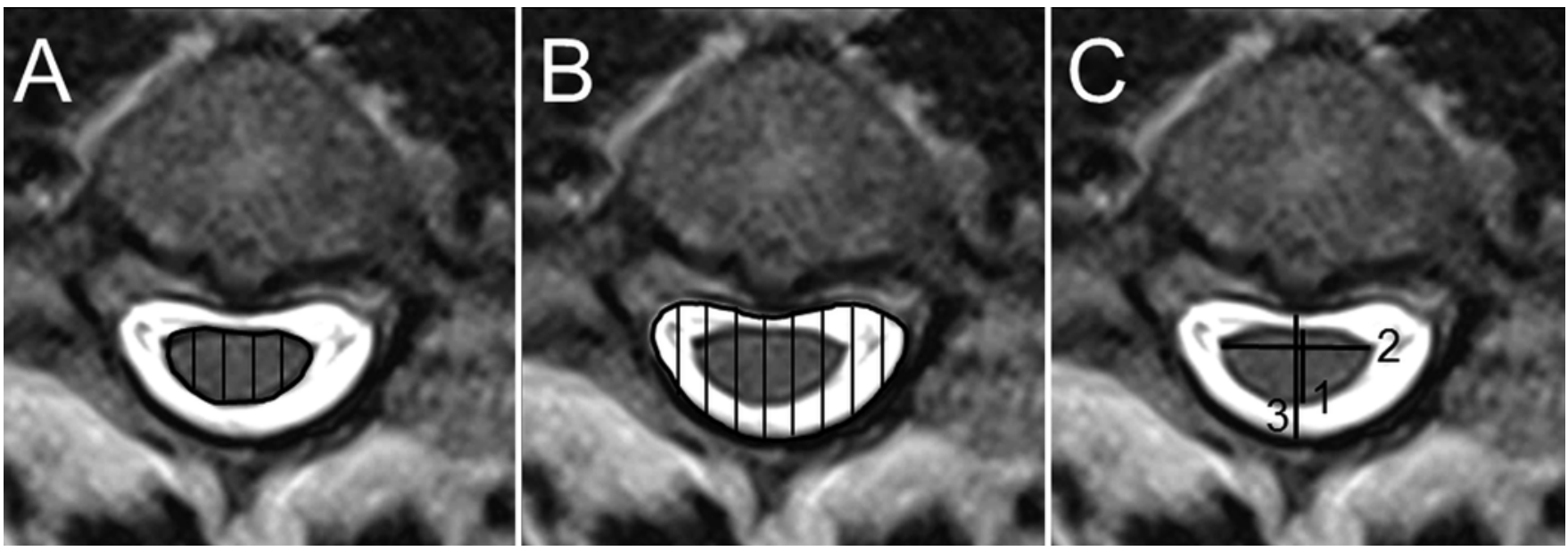

FIG. 2. Axial T2-weighted MR images of the cervical spine showing the parameters measured at the intervertebral disc level: transverse spinal cord area (A), transverse spinal canal area (subarachnoid space) (B), sagittal spinal cord diameter (1), transverse spinal cord diameter (2), and sagittal spinal canal diameter (3) (C).

patients had experienced a median improvement of 16.7 MIS (95\% CI -9.8 to 34.7). After 12 months, all patients had experienced motor deficit improvement. The median MIS was 69.0 (95\% CI 10.3-99.6), which corresponded to a median improvement of 43.5 (2.4-71.4) and a median RR of 0.59 (95\% CI 0.09-0.99); for 7 patients, the total MIS after 12 months was greater than 90 .

The correlations between the imaging parameters and the initial MIS as well as the MIS, MIS improvement, and the RR at 3 and 12 months after the trauma were weak (correlation coefficient $r<0.5)$ and not significant $(p>$ $0.05)$.

\section{Discussion}

Acute CSCI after a minor trauma represents a severe threat for patients with cervical spinal canal stenosis. To the best of our knowledge, ours is the first investigation of the value of these MRI parameters (transverse spinal cord, transverse spinal canal area, and spinal cord com-

\section{TABLE 1. Patient characteristics}

\begin{tabular}{lcc}
\hline Characteristic & $\begin{array}{c}\text { CSCl Group* } \\
(n=52)\end{array}$ & $\begin{array}{c}\text { Control Group* } \\
(n=77)\end{array}$ \\
\hline Sex & & \\
\hline M & $40(77)$ & $48(62)$ \\
\hline F & $12(23)$ & $29(38)$ \\
\hline Age (yrs) & & \\
\hline Median & 54 & 51 \\
\hline Range & $20-82$ & $34-80$ \\
\hline Type of trauma & & \\
\hline Fall & $25(48)$ & $21(27)$ \\
\hline Traffic accident & $15(29)$ & $47(61)$ \\
\hline Winter sports accident & $7(13)$ & $2(3)$ \\
\hline Diving accident & $3(6)$ & $1(1)$ \\
\hline Flying accident & $2(4)$ & $4(5)$ \\
\hline Other accident & $2(4)$ & $2(3)$ \\
\hline
\end{tabular}

* Data are presented as the number (\%) unless otherwise indicated. pression ratio) for the diagnosis of critical spinal canal stenosis and the prediction of the severity of acute CSCI after a minor trauma to the cervical spine. The hypothesis, that the transverse spinal canal area and the spinal cord compression ratio differ significantly between patients with and without acute CSCI after a minor trauma to the cervical spine, was confirmed. The hypothesis concerning the transverse spinal cord area was rejected. The classification accuracy for CSCI reached values greater than $90 \%$ and was best for the cord-canal-area ratio and the space available for cord. However, no significant correlation was found between any of the imaging parameters and the severity of or recovery from CSCI after the trauma.

\section{Classification Accuracy of Imaging Parameters}

Cutoff values of 0.8 for the cord-canal-area ratio and $1.2 \mathrm{~mm}$ for the space available for cord yielded the greatest positive likelihood ratios for the occurrence of CSCI after a minor trauma. The positive likelihood ratios were greater than 10 for these 2 parameters, indicating a greatly increased risk for acute CSCI after a minor trauma if the parameters were below the above-mentioned cutoff values. The positive likelihood ratio provides an estimate of how much a test result will change the odds of having a

TABLE 2. Interobserver and intraobserver reliability for MRI measurements

\begin{tabular}{lccc}
\hline & \multicolumn{2}{c}{ Intraobserver ICC $(95 \% \mathrm{Cl})^{*}$} & $\begin{array}{c}\text { Interobserver ICC } \\
(95 \% \mathrm{Cl})^{*}\end{array}$ \\
\cline { 2 - 4 } Variable & Rater 1 & Rater 2 & $0.94(0.84-0.97)$ \\
\hline $\mathrm{A}_{\text {cord }}$ & $0.97(0.93-0.99)$ & $0.97(0.93-0.99)$ & $0.98(0.97-0.99)$ \\
\hline $\mathrm{A}_{\text {canal }}$ & $0.99(0.98-1.00)$ & $0.99(0.98-1.00)$ & $0.98(0.97-0.82)$ \\
\hline $\mathrm{TD}_{\text {cord }}$ & $0.72(0.50-0.90)$ & $0.75(0.54-0.92)$ & $0.72(0.57-0.92)$ \\
\hline $\mathrm{SD}_{\text {cord }}$ & $0.80(0.62-0.94)$ & $0.84(0.68-0.95)$ & $0.77(0.64-0.85)$ \\
\hline $\mathrm{SD}_{\text {canal }}$ & $0.92(0.82-0.98)$ & $0.97(0.94-0.99)$ & $0.93(0.88-0.96)$ \\
\hline
\end{tabular}

$A_{c a n a l}=$ transverse spinal canal area; $A_{\text {cord }}=$ transverse spinal cord area; ICC = $=$ intraclass correlation coefficient of absolute agreement of single measures; $\mathrm{SD}_{\text {canal }}=$ sagittal spinal canal diameter; $\mathrm{SD}_{\text {cord }}=$ sagittal spinal cord diameter; $\mathrm{TD}_{\text {cord }}=$ transverse spinal cord diameter.

* All data were significant at $p<0.001$. 
TABLE 3. Imaging parameters for assessing cervical spinal canal stenosis

\begin{tabular}{|c|c|c|}
\hline Parameter & $\begin{array}{c}\text { C3-C7, Median } \\
(95 \% \mathrm{Cl})\end{array}$ & $\begin{array}{c}\text { Min/Max, Median } \\
(95 \% \mathrm{Cl})\end{array}$ \\
\hline \multicolumn{3}{|l|}{ TPR } \\
\hline $\mathrm{CSCl}$ & $0.81(0.77-0.85)^{*}$ & $0.73(0.69-0.77)^{*}$ \\
\hline Control & $1.01(0.96-1.05)$ & $0.87(0.84-0.91)$ \\
\hline \multicolumn{3}{|l|}{$\mathrm{SD}_{\text {canal }}(\mathrm{mm})$} \\
\hline $\mathrm{CSCl}$ & $8.8(8.4-9.2)^{*}$ & $7.4(7.1-7.7)^{*}$ \\
\hline Control & $11.0(10.7-11.3)$ & $9.8(9.5-10.1)$ \\
\hline \multicolumn{3}{|l|}{$\mathrm{SD}_{\text {cord }}(\mathrm{mm})$} \\
\hline $\mathrm{CSCl}$ & $7.0(6.8-7.3)$ & $6.2(6.0-6.4)^{*}$ \\
\hline Control & $7.3(7.2-7.5)$ & $6.7(6.6-6.9)$ \\
\hline \multicolumn{3}{|l|}{$\mathrm{TD}_{\text {cord }}(\mathrm{mm})$} \\
\hline $\mathrm{CSCl}$ & $14.0(13.6-14.3)$ & $12.1(11.7-12.4)$ \\
\hline Control & $13.8(13.6-14.1)$ & $12.2(12.0-12.5)$ \\
\hline \multicolumn{3}{|l|}{$\mathrm{A}_{\text {cord }}\left(\mathrm{mm}^{2}\right)$} \\
\hline $\mathrm{CSCl}$ & $80.8(77.0-84.6)$ & $96.7(91.3-102.1) \dagger$ \\
\hline Control & $82.8(80.3-85.4)$ & $91.27(88.2-94.4) \dagger$ \\
\hline \multicolumn{3}{|l|}{$\mathrm{A}_{\text {canal }}\left(\mathrm{mm}^{2}\right)$} \\
\hline $\mathrm{CSCl}$ & $116.5(109.9-123.1)^{\star}$ & $92.0(87.1-96.8)^{*}$ \\
\hline Control & $167.4(160.3-174.5)$ & $139.8(133.5-146.1)$ \\
\hline \multicolumn{3}{|l|}{ CCAR } \\
\hline $\mathrm{CSCl}$ & $0.71(0.68-0.75)^{*}$ & $0.92(0.89-0.94)^{*} \dagger$ \\
\hline Control & $0.51(0.49-0.53)$ & $0.60(0.57-0.62) \dagger$ \\
\hline \multicolumn{3}{|l|}{$\mathrm{CR}$} \\
\hline $\mathrm{CSCl}$ & $0.51(0.50-0.53)$ & $0.44(0.42-0.46)^{*}$ \\
\hline Control & $0.54(0.52-0.55)$ & $0.49(0.48-0.50)$ \\
\hline \multicolumn{3}{|l|}{$\mathrm{SAC}(\mathrm{mm})$} \\
\hline $\mathrm{CSCl}$ & $1.8(1.5-2.1)^{\star}$ & $0.4(0.3-0.6)^{*}$ \\
\hline Control & $3.6(3.3-3.8)$ & $2.6(2.4-2.8)$ \\
\hline
\end{tabular}

$\mathrm{A}_{\text {canal }}=$ transverse spinal canal area; $A_{\text {cord }}=$ transverse spinal cord area; CCAR

= canal-to-cord-area ratio; $C R=$ compression ratio; $\max =$ maximal value; $\min$

$=$ minimal value; $\mathrm{SAC}=$ space available for cord; $\mathrm{SD}_{\text {canal }}=$ sagittal spinal canal diameter; $\mathrm{SD}_{\text {cord }}=$ sagittal spinal cord diameter; $\mathrm{TD}_{\text {cord }}=$ transverse spinal cord diameter.

* Differed significantly from that for control group $(p<0.001)$.

$\uparrow$ Maximum values. condition and includes both sensitivity and specificity. The areas under the ROC curve were 0.99 and 0.98 for the cord-canal-area ratio and space available for cord, respectively, which indicates almost perfect discrimination between patients with CSCI and those without. The classification accuracies of the cord-canal-ratio and the space available for cord, based on area measurements, have not yet been investigated. Authors investigating the relationship between the development of neurological impairment and spinal canal stenosis by using the spinal cord and canal area have not submitted the parameters to ROC curve analysis. ${ }^{11,16}$ In previous studies, the cord-canal-ratio and space available for cord were calculated by using cord and canal diameter measurements. The classification accuracy of the diameter ratios reached values from 0.81 to $0.92 .1,13$ These values correspond with our results for the sagittal canal diameter (0.93). The classification accuracy of the area ratios is therefore superior to the diameter ratios, which is not surprising, given that spinal canal stenosis is not limited to the sagittal plane.

The classification accuracy of the TPR was significantly (no overlap of $95 \% \mathrm{CI}$ ) lower than that for MRI parameters, except for the compression ratio and the sagittal cord diameter. Our results thus corroborate previously reported results concerning the superiority of MRI parameters for the assessment of spinal canal stenosis compared with the TPR measured on conventional radiographs. ${ }^{17,13,18}$ However, the cord dimensions by themselves did not prove to be good classifiers for acute CSCI after a minor trauma. The classification accuracy of the compression ratio (0.74) and the sagittal cord diameter (0.72) were even lower than the accuracy of the TPR (0.78). Naturally, the spinal cord size represents only one side of the coin and the canal dimensions the other. The spinal cord dimensions might be more relevant for injury severity; however, we did not observe any correlation between cord parameters and neurological impairment or recovery.

\section{Characterization of Spinal Canal Stenosis}

In our study, all investigated parameters, notably the MRI parameters apart from the cord area and the transverse cord diameter, were characteristic for patients with acute CSCI after a minor trauma. The average transverse

TABLE 4. Effectiveness of imaging parameters for the diagnosis of $\mathrm{CSCl}$ after a minor trauma to the cervical spine

\begin{tabular}{|c|c|c|c|c|c|c|c|c|}
\hline Parameter (critical value) & Sensitivity (\%) & Specificity (\%) & PPV (\%) & NPV (\%) & Accuracy (\%) & Positive LR & Negative LR & AUC $(95 \% \mathrm{Cl})$ \\
\hline $\operatorname{TPR}_{\min }(0.8)$ & 69 & 72 & 63 & 76 & 71 & 2.5 & 0.4 & $0.78(0.69-0.88)$ \\
\hline $\mathrm{SDcanal}_{\min }(8 \mathrm{~mm})$ & 75 & 95 & 91 & 85 & 87 & 14.4 & 0.3 & $0.93(0.89-0.98)$ \\
\hline $\operatorname{SDcord}_{\min }(6.3 \mathrm{~mm})$ & 60 & 78 & 65 & 74 & 71 & 2.7 & 0.5 & $0.72(0.63-0.81)$ \\
\hline Acanal $_{\min }\left(112 \mathrm{~mm}^{2}\right)$ & 88 & 87 & 82 & 92 & 88 & 6.8 & 0.1 & \multirow{2}{*}{$0.93(0.89-0.98)$} \\
\hline Acanal $_{\min }\left(114 \mathrm{~mm}^{2}\right)$ & 90 & 84 & 80 & 93 & 87 & 5.8 & 0.1 & \\
\hline $\mathrm{CCAR}_{\max }(0.75)$ & 98 & 94 & 91 & 99 & 95 & 15.1 & 0.0 & \multirow{2}{*}{$0.99(0.97-1.00)$} \\
\hline $\mathrm{CCAR}_{\max }(0.8)$ & 90 & 99 & 98 & 94 & 95 & 69.6 & 0.1 & \\
\hline $\mathrm{CR}_{\min }(0.45)$ & 58 & 78 & 64 & 73 & 70 & 2.6 & 0.5 & $0.74(0.66-0.83)$ \\
\hline $\mathrm{SAC}_{\text {min }}(1.2 \mathrm{~mm})$ & 87 & 97 & 96 & 91 & 93 & 33.3 & 0.1 & \multirow[b]{2}{*}{$0.98(0.95-0.99)$} \\
\hline $\mathrm{SAC}_{\min }(1.4 \mathrm{~mm})$ & 94 & 94 & 91 & 96 & 94 & 14.5 & 0.1 & \\
\hline
\end{tabular}

$\mathrm{Acanal}_{\min }=$ minimal transverse spinal canal area; $\mathrm{AUC}=$ area under the curve; $\mathrm{CCAR}_{\max }=$ maximal canal-to-cord-area ratio; $\mathrm{CR}_{\min }=$ minimal compression ratio; $\mathrm{LR}=$ likelihood ratio; NPV = negative predictive value; $\mathrm{PPV}=$ positive predictive value; $\mathrm{SAC}_{\min }=$ minimal space available for cord; $\mathrm{SDcanal}_{\min }=$ minimal sagittal spinal canal diameter; $\mathrm{SDcord}_{\min }=$ minimal sagittal spinal canal diameter; TPR $_{\min }=$ minimal TPR. 
TABLE 5. Motor index scores and neurological improvement of the CSCl patients

\begin{tabular}{ccccc}
\hline & & \multicolumn{3}{c}{ Median Value $(95 \% \mathrm{CI})$} \\
\cline { 3 - 5 } Time After Injury & Sample Size & MIS & RR & MIS Improvement \\
\hline Initial & 37 & $24.5(2.5-99.1)$ & Not applicable & Not applicable \\
\hline 1 mo & 35 & $48.0(2.8-93.5)$ & $0.23(-1.4$ to 0.56$)$ & $16.7(-9.8$ to 34.7$)$ \\
\hline 3 mos & 32 & $64.0(7.8-95.9)$ & $0.52(-0.04$ to 0.80$)$ & $40.0(-3.0$ to 62.1$)$ \\
\hline 12 mos & 35 & $69.0(10.3-99.6)$ & $0.59(0.09-0.99)$ & $43.5(2.4-71.4)$ \\
\hline
\end{tabular}

cord area in both groups measured approximately 80 $\mathrm{mm}^{2}$, which corresponds to the values reported in the literature. ${ }^{8,12,16}$ However, in our study, the average transverse area of the spinal canal (approximately 90 and $140 \mathrm{~mm}^{2}$ for the CSCI and control groups, respectively) was smaller than reported values (approximately $200 \mathrm{~mm}^{2}$ ). ${ }^{12,16}$ These previous measurements were taken at the midvertebral level, whereas our measurements were taken at the level of the intervertebral disc. To identify the critical size of the canal area, measurements should thus be performed at the disc level.

\section{Correlation Between Imaging Parameters and Neurological Impairment or Recovery}

In previous studies, no correlation between spinal canal imaging parameters and the severity of or recovery from acute CSCI, described by the ASIA Impairment Scale, was observed..$^{1,16}$ To improve the sensitivity of our investigation of the association between canal stenosis and CSCI, we therefore used the MIS of the ASIA key muscles to characterize CSCI. However, we observed no significant correlation between the MIS and any of the imaging parameters. The discrepancy between the severity of spinal canal stenosis and CSCI may be the result of dynamic spinal canal changes during a hyperextension trauma, differences in trauma severity, or posttraumatic injury (e.g., edema formation). ${ }^{10,15}$

\section{Limitations}

The limitations of our study include its retrospective design. The prevalence of spinal canal stenosis in the general population is unknown, and there are unidentified differences between patients in the trauma severity. Furthermore, patient selection bias may exist as a result of investigating patients who sought care at our institution. Last, blinded assessment of the imaging parameters was not possible because the group association was obvious from the images. Prospective studies are needed to repeat and validate our results.

\section{Clinical Relevance}

According to our results, the evaluation of critical cervical spinal canal stenosis using MRI parameters, such as the canal-to-cord-area ratio and the space available for the cord, enables discrimination between patients at risk for CSCI and those not at risk; sensitivity and specificity are greater than $90 \%$. Measuring and calculating MRI parameters provides relevant additional information compared with the simple TPR, despite limitations inherent to the MRI technique (e.g., CSF pulsation artifacts, chemical shift artifacts, accumulation of hypointense anatomical structures). ${ }^{3}$ The risk for trauma-induced CSCI can be assessed by applying a cutoff value of 0.8 for the cord-canal-area ratio with a false-negative rate of $10 \%$ and a false-positive rate of $1 \%$. However, the cutoff values presented herein should not be used as the sole indication to restrict activities or perform prophylactic surgical interventions. They might, however, represent valuable additional information concerning further diagnostic or therapeutic steps when assessing cervical spinal canal stenosis.

\section{Conclusions}

The cord-canal-area ratio $(>0.8)$ or the space available for the cord $(<1.2 \mathrm{~mm})$ measured on MR images can be used to identify patients at risk for acute CSCI after a minor trauma to the cervical spine; the sensitivity and specificity of these parameters are high. However, imaging characteristics of the spinal canal do not seem to be associated with the severity of or recovery from CSCI after a minor trauma.

\section{References}

1. Aebli N, Rüegg TB, Wicki AG, Petrou N, Krebs J: Predicting the risk and severity of acute spinal cord injury after a minor trauma to the cervical spine. Spine J 13:597-604, 2013

2. Aebli N, Wicki AG, Rüegg TB, Petrou N, Eisenlohr H, Krebs $\mathrm{J}$ : The Torg-Pavlov ratio for the prediction of acute spinal cord injury after a minor trauma to the cervical spine. Spine J 13:605-612, 2013

3. Bammer R, Fazekas F, Augustin M, Simbrunner J, StrasserFuchs S, Seifert T, et al: Diffusion-weighted MR imaging of the spinal cord. AJNR Am J Neuroradiol 21:587-591, 2000

4. Chung SS, Lee CS, Chung KH: Factors affecting the surgical results of expansive laminoplasty for cervical spondylotic myelopathy. Int Orthop 26:334-338, 2002

5. Ditunno JF Jr, Young W, Donovan WH, Creasey G: The international standards booklet for neurological and functional classification of spinal cord injury. Paraplegia 32:70-80, 1994

6. Green C, Butler J, Eustace S, Poynton A, O'Byrne JM: Imaging modalities for cervical spondylotic stenosis and myelopathy. Adv Orthop 2012:908324, 2012

7. Herzog RJ, Wiens JJ, Dillingham MF, Sontag MJ: Normal cervical spine morphometry and cervical spinal stenosis in asymptomatic professional football players. Plain film radiography, multiplanar computed tomography, and magnetic resonance imaging. Spine (Phila Pa 1976) 16 (6 Suppl):S178S186, 1991

8. Karpova A, Arun R, Davis AM, Kulkarni AV, Mikulis DJ, Sooyong C, et al: Reliability of quantitative magnetic resonance imaging methods in the assessment of spinal canal stenosis and cord compression in cervical myelopathy. Spine (Phila Pa 1976) 38:245-252, 2013

9. Lucas JT, Ducker TB: Motor classification of spinal cord 
injuries with mobility, morbidity and recovery indices. Am Surg 45:151-158, 1979

10. Machino M, Yukawa Y, Ito K, Nakashima H, Kato F: Dynamic changes in dural sac and spinal cord cross-sectional area in patients with cervical spondylotic myelopathy: cervical spine. Spine (Phila Pa 1976) 36:399-403, 2011

11. Okada Y, Ikata T, Katoh S, Yamada H: Morphologic analysis of the cervical spinal cord, dural tube, and spinal canal by magnetic resonance imaging in normal adults and patients with cervical spondylotic myelopathy. Spine (Phila Pa 1976) 19:2331-2335, 1994

12. Prasad SS, O'Malley M, Caplan M, Shackleford IM, Pydisetty RK: MRI measurements of the cervical spine and their correlation to Pavlov's ratio. Spine (Phila Pa 1976) 28:12631268,2003

13. Presciutti SM, DeLuca P, Marchetto P, Wilsey JT, Shaffrey C, Vaccaro AR: Mean subaxial space available for the cord index as a novel method of measuring cervical spine geometry to predict the chronic stinger syndrome in American football players. J Neurosurg Spine 11:264-271, 2009

14. Regenbogen VS, Rogers LF, Atlas SW, Kim KS: Cervical spinal cord injuries in patients with cervical spondylosis. AJR Am J Roentgenol 146:277-284, 1986

15. Shin JJ, Jin BH, Kim KS, Cho YE, Cho WH: Intramedullary high signal intensity and neurological status as prognostic factors in cervical spondylotic myelopathy. Acta Neurochir (Wien) 152:1687-1694, 2010

16. Song KJ, Choi BW, Kim SJ, Kim GH, Kim YS, Song JH: The relationship between spinal stenosis and neurological outcome in traumatic cervical spine injury: an analysis using Pavlov's ratio, spinal cord area, and spinal canal area. Clin Orthop Surg 1:11-18, 2009

17. Torg JS, Corcoran TA, Thibault LE, Pavlov H, Sennett BJ, Naranja RJ Jr, et al: Cervical cord neurapraxia: classification, pathomechanics, morbidity, and management guidelines. J Neurosurg 87:843-850, 1997

18. Torg JS, Naranja RJ Jr, Pavlov H, Galinat BJ, Warren R, Stine RA: The relationship of developmental narrowing of the cervical spinal canal to reversible and irreversible injury of the cervical spinal cord in football players. J Bone Joint Surg Am 78:1308-1314, 1996

19. Torg JS, Pavlov H, Genuario SE, Sennett B, Wisneski RJ, Robie BH, et al: Neurapraxia of the cervical spinal cord with transient quadriplegia. J Bone Joint Surg Am 68:1354-1370, 1986

20. Yue WM, Tan SB, Tan MH, Koh DC, Tan CT: The Torg-Pavlov ratio in cervical spondylotic myelopathy: a comparative study between patients with cervical spondylotic myelopathy and a nonspondylotic, nonmyelopathic population. Spine (Phila Pa 1976) 26:1760-1764, 2001

\section{Author Contributions}

Conception and design: Krebs, Aebli. Acquisition of data: Rüegg, Wicki. Analysis and interpretation of data: Krebs, Rüegg, Wicki. Drafting the article: Krebs, Rüegg, Wicki. Critically revising the article: Krebs, Wisianowsky. Reviewed submitted version of manuscript: all authors. Approved the final version of the manuscript on behalf of all authors: Krebs. Statistical analysis: Krebs, Rüegg, Wicki. Administrative/technical/material support: Aebli, Wisianowsky. Study supervision: Krebs.

\section{Correspondence}

Jörg Krebs, Clinical Trial Unit, Swiss Paraplegic Centre, CH-6207 Nottwil, Switzerland. email: joerg.krebs@ paraplegie.ch. 